\title{
The Influence of Academic Independent Directors and Confucianism on Carbon Information Disclosure: Evidence from China
}

\author{
Ren He $\mathbb{D}^{\mathbb{D}},{ }^{1,2}$ Mingdian Zhou $\mathbb{D}^{1},{ }^{1} J^{\prime n g}$ Liu $\mathbb{D}^{1},{ }^{1}$ and Qing Yang $\mathbb{D}^{2}$ \\ ${ }^{1}$ School of Maritime Economics and Management, Dalian Maritime University, Dalian 116026, China \\ ${ }^{2}$ School of Economics, Fudan University, Shanghai 200433, China \\ Correspondence should be addressed to Qing Yang; qyang@fudan.edu.cn
}

Received 19 November 2020; Revised 5 February 2021; Accepted 20 February 2021; Published 5 March 2021

Academic Editor: Wei Zhang

Copyright (C) 2021 Ren He et al. This is an open access article distributed under the Creative Commons Attribution License, which permits unrestricted use, distribution, and reproduction in any medium, provided the original work is properly cited.

\begin{abstract}
As global warming has received widespread attention, the disclosure of firms' carbon information has been expected by increasing stakeholders. This study extends the previous literature on the determinants of firms' carbon information disclosure by examining the influence of academic independent directors and Confucianism on the quality of carbon information disclosure. Using a sample of Chinese listed firms in the CSI 300 Index during the period of 2012-2018, our empirical results show that academic independent directors have a significantly positive association with the quality of carbon information disclosure. The results also reveal that Confucianism positively affects the quality of carbon information disclosure. Moreover, Confucianism positively moderates the relationship between academic independent directors and the quality of carbon information disclosure. The results imply that Confucianism, as an informal system, can promote the governance effect of academic independent directors on firms' carbon information disclosure behaviour. Our findings offer shareholders, regulators, and other stakeholders an integrating perspective on motivating firms to disclose high quality carbon information.
\end{abstract}

\section{Introduction}

Global warming is one of the greatest concerns in the twenty-first century, and firms can be both the main culprit and problem solver of the greenhouse effects [1]. Several countries have implemented mandatory schemes that require disclosure of greenhouse gas (GHG) emissions, such as Australia, Canada, France, Japan, the United Kingdom, and the United States. China has not formulated mandatory carbon information disclosure (CID) requirements yet; thus, the carbon information disclosed by firms can be regarded as voluntary [2]. It is widely known that China's economy has developed rapidly and its international status has been improved at a high speed. However, China's environmental problems in recent years have attracted worldwide attention [3]. China has become the largest carbon emitter, with its emissions of $\mathrm{CO}_{2}$ accounting for $28 \%$ of the total amount [4]. To reverse the situation, China made a significant U.S.-
China Joint Presidential Statement on Climate Change on 25 September 2015, pledging to lower carbon dioxide emissions per unit of GDP by $60 \%$ to $65 \%$ from 2015 level by 2030 [5], which leads China to a tremendous pressure of energy saving and emissions reduction [6]. Therefore, shareholders intend to monitor and supervise firms' carbon emissions better, which is one of the biggest motivators that China's CID has grown steadily in both quality and quantity in recent years [7].

Previous research on CID either used Carbon Disclosure Project (CDP) data [8-10] or content analysis method $[7,11,12]$ for measuring the quality of CID. In view of the relatively low level of respondence to CDP by Chinese firms [13], we choose the content analysis method to measure the quality of CID. The research on the influencing factors of CID mainly focuses on the following aspects: (1) the firm's internal factors, such as profitability, leverage, size, and industry [12], environmental committee [14], environmental 
management accounting [15]. (2) The firm's external factors, such as stakeholder engagement [16], and environmental legitimacy [13]. Nevertheless, there are very few studies on the influencing factors of CID from a cultural perspective. The motivation of this study arises from that so little research focuses on the role of culture in CID, especially Confucianism. And, previous research also provides little evidence on the effect of academic independent director (AID) on firms' CID.

According to agency theory, corporate governance can reduce agency conflicts and protect the interests of stakeholders in the information disclosure behaviour of firms [17]. Independent directors may be a trustworthy mechanism in resolving agency conflicts on this issue [18]. They can supervise as well as advise. Explicitly, academics are the incarnation of wisdom [19], an independent thinker [20], and have a higher sense of morality and social responsibility [21]. Due to the unique characteristics and role of AIDs, there is sufficient reason to believe that they are environmentally sensitive and have a positive effect on CID.

Unity of Man and Nature (天人合一) is one of the creative wisdom achievements of Confucianism ecological concept. The emphasis on the virtues of Confucianism that human should respect for nature has a positive influence on ecological education [22]. Studies have found that ecological awareness affects people's sense of social responsibility, which in turn affects people's behaviour and practices [23]. And, corporate social responsibility induces firms to create value for the environment and society and reduce the occurrence of environmental problems [24]. Therefore, it is reliable that Unity of Man and Nature will affect the management's attitude and decision-making towards energy conservation and emission reduction, which in turn affects corporate social responsibility behaviour and enables firms to accelerate the pace of carbon emission reduction. Based on signaling theory, managers will release information that is beneficial to firms. Firms with good environmental performance are more inclined to disclose environmental information. Therefore, Unity of Man and Nature will make firms more inclined to disclose carbon information.

Moreover, Confucianism emphasizes Respecting Teachers (尊师重道), which is also a traditional Chinese virtue. In the ethics between people advocated by feudal morality, children must obey their father absolutely (父为子 纲). However, another famous saying in traditional culture is “one-day teacher, life-long father" (一日为师, 终身为父), which is a powerful explanation of Confucianism on respecting for teachers. Especially, the work of faculty professors mainly covers three aspects, teaching students, doing research work, and serving the school. The first identity of the AID is the faculty professor. Thus, Respecting Teachers connects Confucian culture with AIDs deeply. Hence, regions that are heavily influenced by Confucianism are more likely to appreciate the value of AIDs; thus, they are expected better performance in their monitoring and advising roles, thereby improving the quality of firms' CID.

Based on agency theory and signal theory, this research analyses the governance effect of AID and Confucianism on promoting the quality of firms' CID and explores the moderating role of Confucianism in the relationship between AID and the quality of firms' CID. This study makes the following contributions to the existing literature. First, to the best of our knowledge, this study is the first to empirically investigate whether Confucianism may influence low carbon behaviour of firms with a specific focus on CID. Existing research have explored the influence of Confucianism on business ethics, gender diversity of the board of directors, expropriation of minority shareholders, and over investment, but they provide little evidence on the effect of Confucianism on particular low carbon behaviour of firms (CID in our case). This study finds that the concept of Unity of Man and Nature helps explain the positive association between Confucianism and CID.

Second, this study extends existing research on AIDs. Existing research have investigated the effect of AIDs on firm performance, innovation, acquisition performance, and CSR performance ratings, but they provide little evidence on the impact of AID on the quality of CID. Thus, the academia and practical circles know little about the relationship between AID, an important component of independent directors in China (account for one third of the independent directors of Chinese A-share listed firms), and the quality of CID.

Third, to the best of our knowledge, this study is the first to explore the moderating role of Confucianism in the governance effect of AIDs. Confucianism emphasizes respect for teachers. And, most AIDs are teachers in universities. But, previous literature provides little evidence on the influence of Confucianism on the governance effect of AIDs [25-27]. This study incorporates the Respecting Teachers in Confucianism into the theoretical framework of the governance effect of AID on CID. This study finds that Confucianism can positively moderate the relationship between AID and the quality of CID, implying that Confucianism can promote the governance effect of AIDs.

Fourth, this study complements the extant studies on the determinant of CID. Extant studies have investigated the influencing factors of CID such as CEO characteristics, female directors, board committee structures, and regulatory pressure of governments. Most of the influencing factors in extant studies belong to formal systems. Extant literature provides little evidence on the influencing mechanism of informal systems such as traditional culture. This study finds that Confucianism, as an informal system, can work together with AIDs to promote firms' CID behaviour.

Finally, focusing on the Chinese context, this study can better investigate the influence of AIDs and Confucianism on CID. There are a large number of AIDs in China, which account for one third of the independent directors in Chinese A-share listed firms. And, China is the cradle land of Confucianism. Using the context of China, this study can better investigate how AIDs (a formal system) and Confucianism (an informal system) work together to motivate firms' CID behaviour. And, the findings based on the context of China can add value to theoretical completeness of previous research on CID based on more developed countries.

The rest of this paper is organized as follows: Section 2 provides the literature review. Section 3 proposes the hypothesis of this research. Section 4 discusses the research 
methodology. Section 5 presents the empirical results. Section 6 draws the conclusions.

\section{Literature Review}

2.1. Independent Directors and Environmental and Social Disclosure. In the existing literature, there are few studies exploring the role played by the board of directors in environmental and social disclosure $[28,29]$. Some studies focus on the characteristics of the board of directors on environmental information disclosure. Empirical studies show that the size of the board of directors is positively correlated with the environmental performance of the firm [30]. Gender diversity is also one of the hot topics in voluntary disclosure research. Firms with more women on board are more likely to disclose climate change information [31, 32].

In the field of corporate governance, the existence of independent directors is widely concerned and discussed. Previous research has shown that the independence of the board of directors is positively related to environmental and social performance $[33,34]$. Independent directors are positively related to environmental and social disclosure $[35,36]$. More independent directors are on the board, a firm is more likely to disclose carbon information $[37,38]$. If the board of directors has more seats of independent directors or an environmental committee exists, firms are more likely to pay attention to environmental transparency and disclose GHG emission information. However, when the independent directors are not active enough and the environmental committee is not large enough, the effect will not be obvious [8]. Some studies also find that independent directors may be reluctant to disclose GHGs and accurate information [39].

\subsection{Determinants of Carbon Information Disclosure.} Previous research has explored the determinants of CID behaviour of the firm. The research mainly covers two aspects. First, the internal influencing factors of disclosing carbon information. The decision to respond to CDP is associated with the firm's existing financial resources, the setting of a certified environmental management system, and the publicity of corporate social responsibility reports [10]. Firm's profitability, leverage, size, and industry are also important determinants of GHG emission disclosure [12]. Lewis et al. find firms led by newly appointed CEOs and those with MBAs are more likely to respond to CDP; nevertheless, those led by lawyers show less interest [40]. The influence of institutional investors is positively associated with the extent and quality of climate change disclosure [41]. The existence of an environmental committee can improve the level of climate change disclosure $[14,38]$. However, the establishment of a separate risk committee has no impact on the firm's voluntary GHG emissions disclosure [42]. Firms in high-emission industries as well as firms with better performance are more willing to disclose carbon information, and when competitors increase, firms tend to disclose more carbon information [7].

Second, in addition to the internal characteristics of firms, the firm's CID will also be affected by the external environment. The institutional pressure, such as the EU's emissions trading scheme and the GRI guidelines, has a positive effect on the quality and scope of firms' GHG emissions reporting [43]. Environmental regulations and legal sources are extremely important to a firm's decisions on CID [44]. The CIDs of state-owned enterprises are more sensitive to the regulatory pressure of local governments, while non-state-owned enterprises are more sensitive to social pressure [2]. Firms registered in countries that ratified the Kyoto Protocol are more likely to disclose GHG emissions information [45].

2.3. Confucianism and Business Practice. As a Chinese traditional culture, Confucianism has an impact on regions that recognize and practice Confucian culture and can serve as a good foundation for the business practices and management models of Chinese firms in the 21st century [46]. Most studies focus on the theoretical value of Confucianism. There are studies on comparing the correlation and worth of Confucian ethics and contemporary business ethics [47]. Some studies have linked interpersonal harmony in Confucian culture with corporate social responsibility [25]. The value of trustworthiness in Confucian culture is also explored [48].

When focusing on how culture works in practice, empirical research shows that culture plays a decisive role in corporate social performance and corporate financial performance [49]. A high-integrity corporate culture can help reduce the burden of external transaction costs for firms [50]. The impact of culture on ethical sensitivity is a decisive factor for corporate governance practices in different areas [51]. There is evidence that Hofstede's cultural dimensions have a significant correlation with corporate social performance [52].

There are few studies on the practical value of Confucian culture. Extant literature shows that Confucianism has a negative correlation with the gender diversity of the board of directors; however, regions with high GDP per capita can weaken this negative impact [27]. Confucianism can also reduce the expropriation of minority shareholders, and this effect enhances in non-state-owned enterprises [26]. Similarly, Confucianism has a negative correlation with over investments; the negative link strengthens in non-stateowned enterprises [53].

Based on the above, the effect of AID on the firm's CID quality has not been explored. And, there is no research on how the firm's CID behaviour is influenced by Chinese traditional culture. This paper explores the effects of AID and Confucianism on the quality of firms' CID. This research has theoretical and practical values for studying the influencing factors of firm's CID in China and for improving the internal governance efficacy of AID and external governance efficacy of Chinese traditional culture.

\section{Theory and Hypotheses}

3.1. Academic Independent Directors and the Quality of Carbon Information Disclosure. Agency theory believes that 
managers may abuse their power and exploit the interests of shareholders. And, agency theory [17] proposes that disclosure behaviour is closely related to corporate governance. Agency theory encourages the use of corporate governance mechanisms to coordinate the contradictions between the principles and agents [37]. Based on this theory, firms will improve the effectiveness of its own corporate governance to enhance its' internal control level and provide a monitoring role to decrease opportunistic behaviour and information asymmetry [54]. Enhancing the independence of the board is a good way to promote the firm's long-term and stable development [35], such as promoting the firm's Environmental, Social, and Governance (ESG) disclosure behaviour [37].

In general, independent directors perform supervisory functions as well as an advising role. However, beyond the independence of directors, the influence of different types of independent directors on corporate governance is not equivalent. Among them, AID has a unique value. Academic directors have a positive relationship with firm performance [20] and corporate social responsibility performance [55]. The impact of AID on corporate governance has three levels. (1) What they can do? Most AIDs are professors with doctoral degrees and possess a wealth of professional knowledge and individual abilities. Undoubtedly, doctoral degrees represent the highest level of education in most countries around the world. The education level of AIDs speaks for their abilities and skills. And, highly educated directors are more likely to understand environmental issues; it is therefore more inclined to contribute to CID. (2) How they do? AIDs have the ability to think independently and objectively. Professors with doctorates generally have a deeper world view and can sagaciously distinguish good ideas from bad ones [19]. AIDs and non-AIDs have different ways of thinking, which can bring fresh and diverse perspectives to the board. Compared with other types of outside directors, AIDs have fewer internal social connections and are more likely to achieve independent thinking [20]. (3) Why they do? Because AIDs have higher moral standards, a stronger sense of social responsibility [55], and care more about their own reputation [56]. The above-mentioned characteristics of AIDs have inspired them to care about environmental issues and promote firms to take action. Based on these, they are expected to make greater contributions to the firm's CID. Therefore, we formulate the following hypothesis:

Hypothesis 1. Academic independent directors positively affect the quality of carbon information disclosure.

\subsection{Confucianism and the Quality of Carbon Information} Disclosure. Confucianism is one of the most significant philosophical and moral systems in China [27]. In the preQin era, Confucius and other representatives created Confucianism which became the mainstream cultural consciousness of Chinese society after being institutionalized. After more than two thousand years of baptism and development, it has gradually become the essence and core of Chinese traditional culture.
Confucianism has some outstanding theories like Confucian traditional ecological consciousness. Confucianism believes that human society exists in the natural environment. Nature provides humans with a series of raw living materials such as food and shelter, and human beings are part of the natural environment. In view of Confucianism, man and nature are essentially similar and common. Based on this theory, Confucianism has developed some superior ecological consciousness such as the Unity of Man and Nature. According to the Unity of Man and Nature, understanding the human-nature relationship as a consumer-commodity relationship is void of sacredness or moral association of the human-nature relationship [57]. Some studies believe that the supreme essence of the Unity of Man and Nature is to bring peace and security to future generations and promote the sustainable development of global society, and the combination of Confucianism and science can help fix the thorny problem of global environmental degradation [58]. Generally speaking, Confucian ecological thinking can affect the decision-making of managers. In particular, firms in areas that are more deeply radiated by Confucianism will pay more attention to energy conservation and emission reduction, and furthermore, improve carbon performance.

Signaling theory emphasizes solving the problem of asymmetry of information between two parties. According to the signaling theory, when a firm's environmental performance is excellent, it will have a strong motivation to break the barriers of information asymmetry and actively disclose environmental information, to distinguish itself from firms with poor environmental performance in front of investors and stakeholders [59]. Furthermore, previous empirical studies believe that signaling theory is a key factor in influencing managers' options regarding CID $[7,60]$. To sum up, the Confucian concept of Unity of Man and Nature will affect the behaviour of managers and promote firms to improve their carbon performance. Based on signaling theory, firms with good carbon performance are more willing to disclose carbon information. Therefore, we formulate the following hypothesis:

Hypothesis 2. Confucianism positively affects the quality of carbon information disclosure.

3.3. Academic Independent Director, Confucianism, and Quality of Carbon Information Disclosure. In Chinese history, some representatives of Confucianism discussed the topic of respecting teachers. Xunzi believes that "For a country to prosper, it must respect its teachers." Confucian classic, the Book of Rites, wrote "Teachers should not only teach students knowledge, but also teach students the principles of life." It is self-evident that the Confucianism of respecting teachers plays an important role in the growth of Chinese people. The first identity of AID is teacher. There are a few researches on the role of AIDs in corporate governance $[19,20,55]$. AIDs have objective thinking and are less affected by others and thus can better supervise the manager's decisions $[56,61]$, and they may bring reputation capital to a 
firm. From the above analysis, it can be seen that firms in areas that are deeply radiated by Confucianism may more praise respecting teachers and may more value the significance of AIDs. When a firm is located in an area with strong Confucianism atmosphere, the advices of AIDs on CID will be more valued and easier to adopt by managers. When a firm is located in an area with weak Confucianism atmosphere, even if the proportion of AIDs is relatively high, their advices on CID are likely to be ignored because they are not valued by managers. Therefore, we formulate the following hypothesis:

Hypothesis 3. Confucianism positively moderates the relationship between academic independent directors and the quality of carbon information disclosure.

\section{Methods}

4.1. Sample and Data Sources. The sample of the study involves large firms, since they hold a greater economic significance, as well as face larger public, political, and institutional pressure than medium and small ones [62], and they are more concerned about their reputation and show more propensity to disclose information voluntarily [59]. For the above two reasons, our initial sample consists of 610 firms in the CSI 300 Index covering a period of 7 years (2012-2018). We collect financial data from the CSMAR database. Subsequently, the CID quality was obtained from the firms' corporate social responsibility reports and annual reports. Following Du [27], we manually collect and compute the data on Confucianism by means of Google-earth map. Of all these 610 firms, 4 firms belonging to the finance and insurance industries were eliminated from the sample. Then, 203 firms were excluded due to missing corporate social responsibility reports and 10 firms were excluded due to unavailable data. The final sample covers 2194 observations from 393 firms.

\subsection{Variables and Models}

4.2.1. Variables. The dependent variable is the quality of CID. Content analysis is a common measurement method in CID research [14, 59]. Considering the objectivity and comparability of the research results, we adopt the CID index used in the previous research to measure the quality of CID [11]. A score of one is assigned if a disclosure is related to items in CID index. We use content analysis to evaluate the total score of 22 items. The specific scoring rules are shown in Table 1.

The independent variable is AID and Confucianism. We download the firms' annual reports from the official website of the Shanghai and Shenzhen Stock Exchange and manually collect the detailed information of each independent director in the reports to see if he or she is a professor or an associate professor in the university. Consistent with prior research, in this study, we employ the percentage of AIDs on board (ACARATIO) as the proxy of AID [55]. We use Googleearth map to find the longitude and latitude of the firm's registered address and the Confucianism center separately and then use the geographic distance between the two to construct Confucianism variables [26, 27].

This research controls for the effect of several variables which have been acknowledged in the extant literature to affect the firm's CID quality, including firm size (SIZE), leverage (LEV), whether the corporate social report is verified by a third party (VERIFICATION), high-carbon industry (HIGH _CARBON), board of directors (BOARDSIZE), return on equity (ROE), firm age (AGE), and the concentration of ownership (CONCENTRATION). The definitions of variables are shown in Table 2.

4.2.2. Models. In this study, ordinary least squares (OLS) regression analysis is used to test our hypotheses. To test Hypothesis 1, we estimate the following regression model:

$$
\begin{aligned}
\mathrm{CID}= & \alpha_{0}+\alpha_{1} \mathrm{ACARATIO}+\alpha_{2} \mathrm{SIZE}+\alpha_{3} \mathrm{LEV}+\alpha_{4} \mathrm{ROE}+\alpha_{5} \mathrm{AGE}+\alpha_{6} \text { BOARDSIZE } \\
& +\alpha_{7} \text { HIGH_CARBON }+\alpha_{8} \text { VERIFICATION }+\alpha_{9} \text { CONCENTRATION }+ \text { YEAR_DUMMIES } \\
& + \text { INDUSTRY_DUMMIES }+\varepsilon_{i, t} .
\end{aligned}
$$

To test Hypothesis 2, we estimate the following regression model:

$$
\begin{aligned}
\mathrm{CID}= & \alpha_{0}+\alpha_{1} \mathrm{CONF} \_\mathrm{R}+\alpha_{2} \mathrm{SIZE}+\alpha_{3} \mathrm{LEV}+\alpha_{4} \mathrm{ROE}+\alpha_{5} \mathrm{AGE}+\alpha_{6} \mathrm{BOARDSIZE}+\alpha_{7} \mathrm{HIGH} \_\mathrm{CARBON} \\
& +\alpha_{8} \text { VERIFICATION }+\alpha_{9} \mathrm{CONCENTRATION}+\text { YEAR_DUMMIES }+ \text { INDUSTRY_DUMMIES }+\varepsilon_{i, t} .
\end{aligned}
$$

To test Hypothesis 3, we estimate the following regression model: 
TABLE 1: Items included in the carbon information disclosure index.

\begin{tabular}{|c|c|c|}
\hline ID & & Category/item \\
\hline $\mathrm{CC}$ & & Climate change-related risks, opportunities, and actions \\
\hline 1 & $\mathrm{CC} 1$ & Risks associated with climate changes \\
\hline 2 & CC2 & Description of the actions initiated or planned as a result of identification of risks associated with climate change \\
\hline 3 & CC3 & Opportunities associated with climate change \\
\hline 4 & CC4 & Actions initiated or planned as a result of identification of opportunities associated with climate change \\
\hline GHG & & GHG emissions accounting \\
\hline 5 & GHG1 & Methodology used to calculate GHG emissions \\
\hline 6 & GHG2 & External verification/assurance status that applies to GHG emissions \\
\hline 7 & GHG3 & Total GHG emissions \\
\hline 8 & GHG4 & Breakdown of GHG emissions \\
\hline 9 & GHG5 & GHG emission intensity \\
\hline 10 & GHG6 & Strategies to reduce GHG emissions \\
\hline 11 & GHG7 & GHG emission reduction plans \\
\hline 12 & GHG8 & GHG emission intensity reduction \\
\hline EC & & Energy consumption accounting \\
\hline 13 & $\mathrm{EC} 1$ & Total energy consumption \\
\hline 14 & $\mathrm{EC} 2$ & Breakdown of energy consumption \\
\hline 15 & EC3 & Total renewable energy consumption \\
\hline 16 & EC4 & Breakdown of renewable energy consumption \\
\hline 17 & EC5 & Strategies to increase renewable energy use \\
\hline 18 & EC6 & Strategies to reduce energy use \\
\hline ACC & & Climate change-related governance and accountability \\
\hline 19 & ACC1 & Board committee responsible for climate change risk management \\
\hline 20 & ACC2 & How the board reviews progress on firms carbon performance \\
\hline 21 & ACC3 & Incentives for managing GHG emissions and energy use \\
\hline 22 & $\mathrm{ACC} 4$ & Staff development programs to encourage reduction of emissions and energy use \\
\hline
\end{tabular}

The index is adopted from Liu et al. [11].

TABLE 2: Variable definition.

\begin{tabular}{|c|c|}
\hline Variables & Description \\
\hline CID & The total score of CID index. \\
\hline ACARATIO & Percentage of academic independent directors on the board of directors. \\
\hline CONF_R & $\begin{array}{c}\text { The number of Confucianism centers within a radius of } R \text { kilometers }(R=200,220,240,260,280,300 \mathrm{~km}) \text { around a firm's } \\
\text { registered address. }\end{array}$ \\
\hline SIZE & Logarithm of the number of employees. \\
\hline LEV & Debt-to-equity ratio. \\
\hline ROE & Return on equity. \\
\hline VERIFICATION & Whether the corporate social responsibility report is verified by a third party. \\
\hline HIGH-CARBON & $\begin{array}{l}\text { Dummy variable that equals } 1 \text { if the firm belongs to a high-carbon industrial sector. High-carbon industries include } \\
\text { automobiles and components, chemicals, forest products, gas and electrical utilities, oil and gas, mining, pipelines, precious } \\
\text { metals, steel, and transportation. }\end{array}$ \\
\hline BOARDSIZE & Total number of board members. \\
\hline AGE & The number of years that have passed since a firm's IPO. \\
\hline CONCENTRATION & The percentage of total common stocks owned by the largest shareholders. \\
\hline
\end{tabular}

TABle 3: Descriptive statistics.

\begin{tabular}{|c|c|c|c|c|c|}
\hline Variables & $\begin{array}{l}(1) \\
N \\
\end{array}$ & $\begin{array}{c}(2) \\
\text { Mean } \\
\end{array}$ & $\begin{array}{l}(3) \\
\text { SD }\end{array}$ & $\begin{array}{l}(4) \\
\min \end{array}$ & $\begin{array}{l}(5) \\
\max \end{array}$ \\
\hline CID & 2,194 & 2.572 & 2.252 & 0 & 15 \\
\hline ACARATIO & 2,194 & 0.207 & 0.114 & 0 & 0.600 \\
\hline CONF_R200 & 2,194 & 0.423 & 0.633 & 0 & 2 \\
\hline CONF_R220 & 2,194 & 0.484 & 0.700 & 0 & 2 \\
\hline CONF_R240 & 2,194 & 0.527 & 0.722 & 0 & 2 \\
\hline CONF_R260 & 2,194 & 0.553 & 0.744 & 0 & 2 \\
\hline CONF_R280 & 2,194 & 0.588 & 0.769 & 0 & 2 \\
\hline CONF_R300 & 2,194 & 0.648 & 0.819 & 0 & 2 \\
\hline SIZE & 2,194 & 4.005 & 0.563 & 1.602 & 5.739 \\
\hline LEV & 2,194 & 0.525 & 0.193 & 0.0156 & 0.982 \\
\hline ROE & 2,194 & 0.0660 & 0.614 & -20.74 & 0.566 \\
\hline AGE & 2,194 & 13.70 & 6.247 & 1 & 33 \\
\hline BOARDSIZE & 2,194 & 9.521 & 2.210 & 5 & 18 \\
\hline HIGH_CARBON & 2,194 & 0.426 & 0.495 & 0 & 1 \\
\hline VERIFICATION & 2,194 & 0.0351 & 0.184 & 0 & 1 \\
\hline CONCENTRATION & 2,194 & 41.58 & 16.36 & 3.620 & 88.55 \\
\hline
\end{tabular}




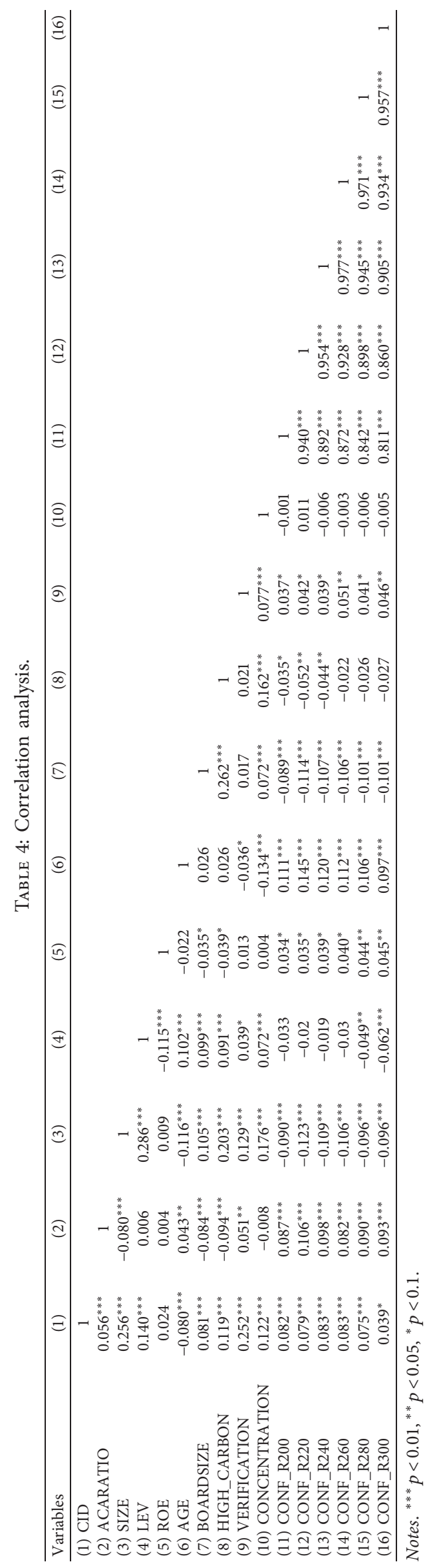


TABle 5: Regression results of Hypothesis 1.

\begin{tabular}{lcc}
\hline Variables & & The dependent variable: CID \\
\hline ACARATIO & Coefficient & $(2.86)$ \\
SIZE & $1.109^{* * *}$ & $(7.52)$ \\
LEV & $0.713^{* * *}$ & $(4.93)$ \\
ROE & $1.447^{* * *}$ & $(2.28)$ \\
AGE & $1.043^{* *}$ & $(-4.96)$ \\
BOARDSIZE & $-0.038^{* * *}$ & $(1.59)$ \\
HIGH_CARBON & 0.033 & $(-2.70)$ \\
VERIFICATION & $-0.326^{* * *}$ & $(10.16)$ \\
CONCENTRATION & $2.406^{* * *}$ & $(1.80)$ \\
Constant & $0.005^{*}$ & $(-4.57)$ \\
Year & $-2.806^{* * *}$ & \\
Industry & Yes & \\
Observations & Yes & \\
R-squared & 2,194 & \\
\hline
\end{tabular}

Notes. $t$ statistics in parentheses. ${ }^{* * *} p<0.01,{ }^{* *} p<0.05,{ }^{*} p<0.1$.

$$
\begin{aligned}
\mathrm{CID}= & \alpha_{0}+\alpha_{1} \mathrm{ACARATIO}+\alpha_{2} \mathrm{CONF} \mathrm{R}+\alpha_{3} \mathrm{ACARATIO} * \mathrm{CONF} \mathrm{R}+\alpha_{4} \mathrm{SIZE}+\alpha_{5} \mathrm{LEV}+\alpha_{6} \mathrm{ROE} \\
& +\alpha_{7} \mathrm{AGE}+\alpha_{8} \mathrm{BOARDSIZE}+\alpha_{9} \mathrm{HIGH} \_\mathrm{CARBON}+\alpha_{10} \mathrm{VERIFICATION} \\
& +\alpha_{11} \mathrm{CONCENTRATION}+\text { YEAR_DUMMIES }+ \text { INDUSTRY_DUMMIES }+\varepsilon_{i, t} .
\end{aligned}
$$

\section{Results}

5.1. Descriptive Statistics and Correlation Analysis. Table 3 presents the descriptive statistical analysis on our sample firms' AIDs, Confucianism, CID, and other variables. The results show that there exists a great gap in CID among firms (the maximum and minimum values are 15 and 0 , respectively). AIDs hold on $20.7 \%$ of the board seats in the board of directors in our sample firms. No matter it is within 200 or 300 kilometers from the registered address of the firm, there are at most two Confucianism centers and at least zero Confucianism center. On average, firms in the CSI 300 Index listed over 13 years. Table 3 also shows that $42.6 \%$ of our sample firms belong to high-carbon industries. Eventually, on average, only $3.51 \%$ of firms have a third-party verification of their social responsibility reports.

The Pearson correlation results are presented in Table 4, as well as the results of the significance test performed to detect whether there is collinearity between the variables in the table. Particularly, the relationship between ACARATIO and CID was found to be equal to 0.056 along with statistical significance at the $1 \%$ level. Therefore, AIDs positively encourage the CID of firms. Moreover, there is also a positive and significant correlation between Confucianism and CID, which means that the ecological concept of Unity of Man and Nature can indeed make the firms more concerned about environmental issues and more willing to disclose carbon information.

\subsection{Hypothesis Tests}

5.2.1. Regression Results of Hypothesis 1. Our first hypothesis confirmed that CID is affected in a statistically significant way by AIDs. All continuous variables were winsorized at the $1 \%$ level to avoid potential outlier effects. The aforementioned result is presented in Table 5. The results show that the coefficients of ACARATIO are positive and significant at the $1 \%$ level across all regression models, which supports the prediction of our first hypothesis. In terms of control variables, we find SIZE, LEV, ROE, VERIFICATION, and CONCENTRATION are all significantly associated with CID in our regression model; we also found that AGE is negatively correlated with CID. HIGH-CARBON has a negative association with CID.

Our regression result shows that AIDs decrease the barriers of communication between the firm and stakeholders and reduce information asymmetry, thus wellplaying their role to stimulate firms to disclose more carbon information. Moreover, the same as the previous study [63], we find that AGE is negatively correlated with CID, this may be because firms with less listing years are more likely to care about their reputation; thus, they intend to increase CID to attract investors' attention. Consistent with Prado-Lorenzo and Garcia-Sanchez [39], the result shows that high-carbon industries have a significant negative correlation with CID; this may be due to the poor carbon performers are reluctant to disclose; nevertheless, good carbon performers possess more willingness to disclose, which supports the signaling theory explanations in the literature $[29,60]$.

5.2.2. Regression Results of Hypothesis 2. The regression results for testing Hypothesis 2 are reported in Table 6. The results show that the regression coefficients for CONF_RN $(R=200,220,240,260,280$, and 300$)$ are significantly positively associated with the CID $(p<0.01)$, which means that firms that are heavily influenced by Confucian culture 


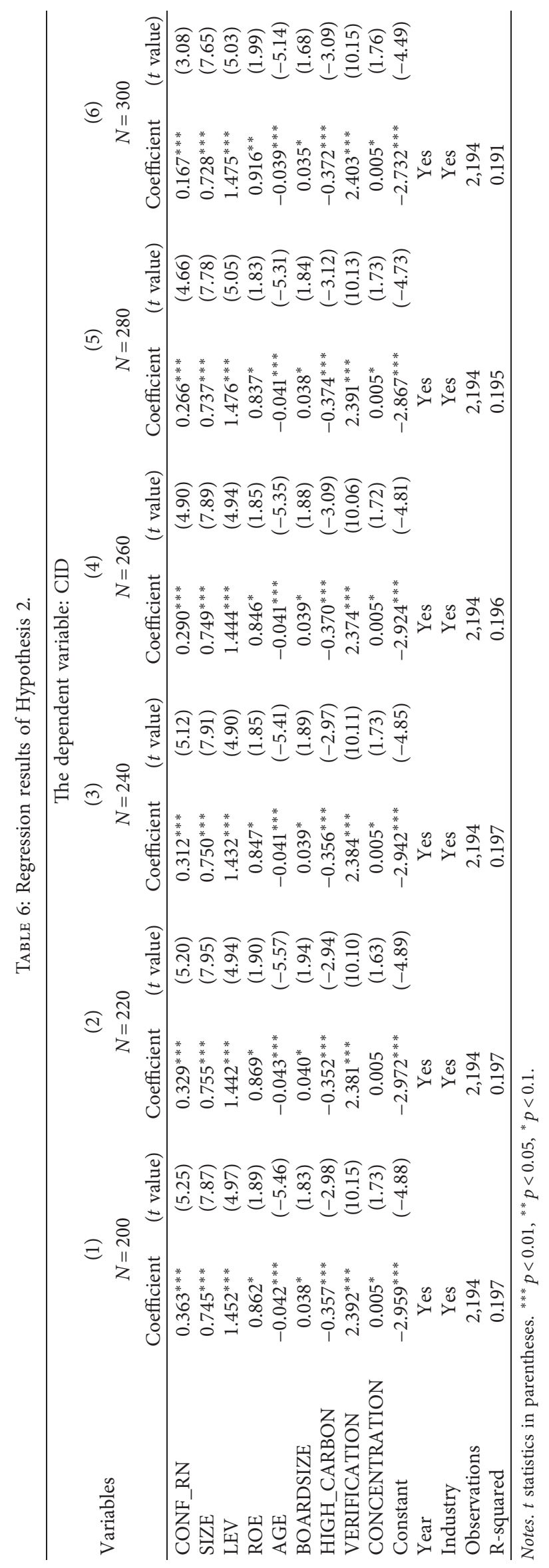




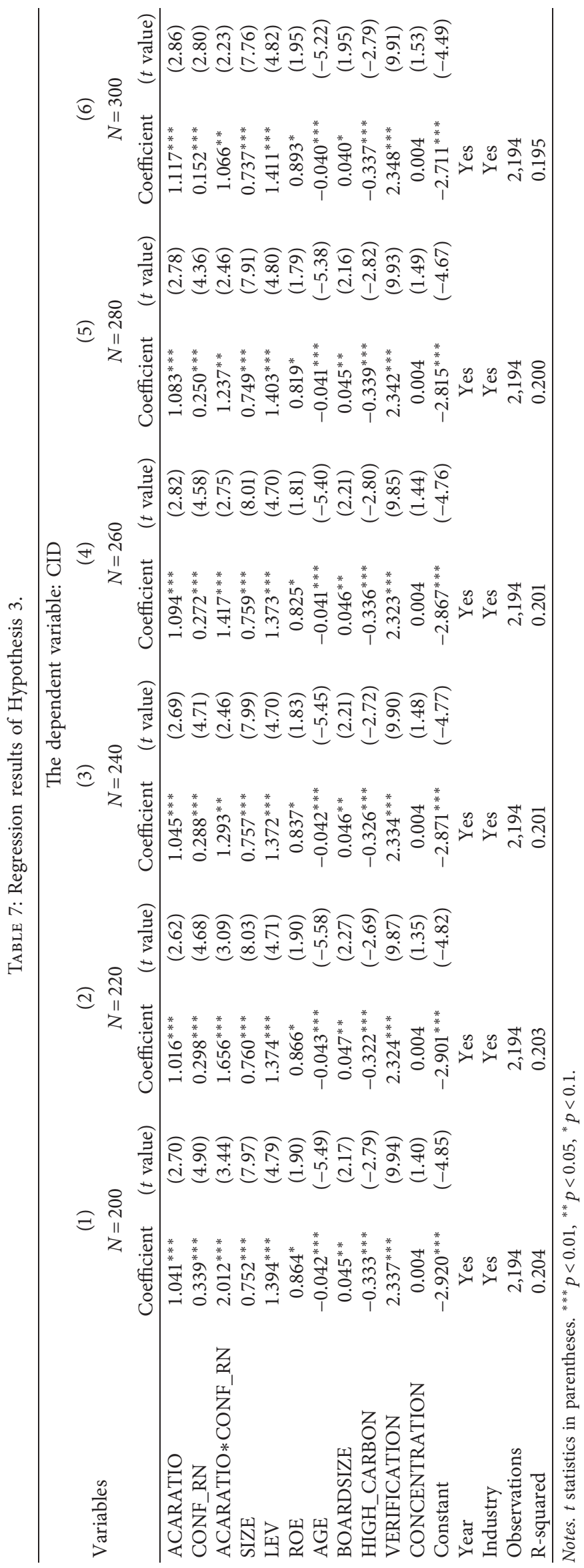


(within 300 kilometers) prefer to disclose carbon information on account of following the philosophical ecological concept of Unity of Man and Nature. The significance of SIZE, LEV, ROE, AGE, HIGH-CARBON, VERIFICATION, and CONCENTRATION has not changed; the sign of the correlation coefficient has not changed either. Thus, Hypothesis 2 is supported. In short, we found that Confucianism has a positive impact on CID.

5.2.3. Regression Results of Hypothesis 3. Table 7 shows that the coefficients of ACARATIO and CONF_RN $(R=200$, $220,240,260,280$, and 300) are positive and significant at the $1 \%$ level, suggesting that they both engender favourable effects on CID, consistent with our expectations in Hypotheses 1 and 2 . The interaction term regression coefficients for ACARATIO $*$ CONF_RN $(R=200,220,240,260,280$, and 300$)$ are significantly positively associated with CID $(p<0.01)$, Hypothesis 3 is therefore supported. AIDs and Confucian culture each have their own special characteristics to positively influence CID. Additionally, the concept of Respecting Teachers in Confucian culture will make firms in areas deeply influenced by Confucianism pay more attention to the value of AIDs. AIDs along with Confucianism can create greater sparks and deepen the promotion of the firm's CID behaviour.

5.2.4. Robustness Tests. One of the purposes of this research is to analyze the correlation between AIDs and CID as presented in Table 5; however, the baseline regression results may be influenced by a potential endogeneity. This is because firms with high levels of CID may have a propensity to recruit AIDs, and AIDs may also be attracted to firms with high levels of CID. Nevertheless, based on the fact that we are studying the largest firms in the Shanghai and Shenzhen stock markets in China, these firms are better than other firms in terms of firm performance, social responsibility, and environmental performance; thus, it is hard to say which factor attracts AIDs. Our sample itself avoids the endogeneity issues to some extent. Hence, as a robust test, first, we use the instrumental variables 2SLS regression analysis approach to alleviate this endogeneity concern. This instrumental variable should be associated with AIDs but not with the error term of the regression results of CID.

According to Francis et al. [20], the distance between the firm headquarter and the university where the professor is appointed is related to the professor director but is unlikely to be related to firm performance. Based on this idea, we choose the number of universities in project 985 (world-class universities) in the city where the firm's registered address is located as our instrumental variable, on account of the large number of universities in project 985 may signify that there will be more AIDs working here; thus, it is related to the AIDs, but is less likely to be related to the quality of the firm's CID. After this test, we find that after considering the potential endogeneity issue, AID is still positively and significantly associated with CID $(p<0.1)$, which again supports our hypothesis.
In addition, we also run further analysis by applying completely different standards to measure our main variables. CID-DUM is a dichotomous variable (a dummy variable that equals one if the firm gets a score, and zero otherwise), which represents the firm's decision to disclose carbon information. The results of this test are consistent with our hypotheses. The measure of Confucianism is also changed to study whether its impact on CID is robust. Following Du [26], we use CONF_R_DUM to reevaluate Confucianism, a dummy variable of CONF_R, equaling 1 if there is one or more Confucianism centers within a radius of $R$ kilometers, $R=200,220,240,260,280$, and $300 \mathrm{~km}$. The results of this test are consistent with those of our hypotheses. We also use the number of AIDs as a new measure to test; the regression results are consistent with our hypotheses. These robustness tests above indicate that our empirical results are robust and credible.

\section{Conclusions}

As the largest carbon emitter, the world's carbon emission reduction trend strongly depends on China's carbon emission reduction status. This paper focuses on large Chinese firms to seek for the key factors related to their CID behaviour. In addition, along with China's unique traditional cultural thoughts which have been passed down for thousands of years and have imperceptibly influenced the Chinese people's ideological system, there are differences between Chinese firms and firms in other countries in how to encourage voluntary CID.

In this paper, we study the influencing factors of CID from a new perspective. We integrate the external governance factor, the traditional Chinese culture (Confucianism, an informal system), and the internal governance factor, the AID (a formal system), into a unified research framework. The results of our research indicate that there is a strong positive correlation between AIDs and CID and provide a significant input to the ongoing discussion on the role of academics on board. Our results contribute to this discussion by showing that academics are not only can take an important part in playing the supervisory and advising roles to reduce the asymmetry of information between the firms and investors but also as a representative of high wisdom independent thinkers and high sense of social responsibility. Our results document that academics can perform excellent on issues related to CID.

Another key finding of our study is that when cultural factor is incorporated into the influencing factors of CID, it produces a positive relationship as well. As the traditional Chinese culture, Confucianism has formed many excellent ecological concepts in the long historical development, such as the Unity of Man and Nature, which emphasizes that man and nature should live in harmony and man should respect and revere nature. Since Confucian culture teaches people to respect nature and thoughts can shape human's behaviour, this ecological concept will also make managers pay more attention to environmental issues and take practical actions to reduce emissions. According to the signaling theory, firms with good carbon emission reduction performance will be 
more prefer to disclose and advertise themselves. Based on this principle, we observe that Confucianism promotes firms to disclose carbon information.

As regards Confucian culture, there is another marvelous tradition of respecting teachers. As the old saying goes, "respecting the teacher is the same as respecting one's father and brother." The teaching profession is generally respected in China with a long history, and AIDs are also university professors, which helps explain that firms in areas heavily affected by Confucianism can better understand the meaning of respecting teachers and they can see the value of AIDs. Therefore, we investigate the moderating role of Confucianism on the relationship between AIDs and CID. We find that Confucianism can enhance the positive impact of AIDs on CID.

In addition to the theoretical contributions listed in the "Introduction" section, the findings of this paper also have some practical implications. First, since AIDs promote firms' CID quality, firms can improve their level of information disclosure related to climate change through appointing AIDs. Second, this study finds that Confucianism can influence the thought of managers and thus affect firm CID behaviour in the context of China. Therefore, Confucianism should not be ignored in academic research and policymaking. Scholars, practitioners, and government should pay more attention to the impact of Confucianism and other traditional cultures on firm behaviour. Third, since Confucianism affects the importance of AIDs, Confucianism, as an informal system, can promote the governance effect of AID. The academia, the practical circle, and regulators should pay attention to the external environment of AIDs. Academia and the government should actively promote the dissemination of Confucianism, which can promote the governance effect of AIDs and improve corporate governance. For listed firms in areas with a strong Confucianism atmosphere, appointing AIDs will be beneficial.

As in all empirical studies, our study has several limitations. First, the CID index used in our study may not have captured all necessary information which can measure the quality of CID. Second, aiming at capturing the influence of Confucianism atmosphere around a firm, we use the number of Confucianism centers within a particular radius around a firm as the proxy of Confucianism to capture the influence level of Confucianism atmosphere around a firm, which based on the assumption that the Confucianism atmospheres around different Confucianism centers are the same. In fact, the levels of Confucianism atmosphere around different Confucianism centers may be different. Third, our study focuses on a sample of relatively large firms in China (CSI 300). Therefore, our results may not hold for small firms, or firms outside China. The role and influences of AIDs and Confucianism may vary across countries. But, our findings may be applied to other Asian countries where Confucianism historically existed, such as Japan, Korea, Singapore, and Vietnam, which inspires further discussion and testing by scholars.

\section{Data Availability}

The data used to support this study are available from the corresponding author upon request.

\section{Conflicts of Interest}

The authors declare that there are no conflicts of interest regarding the publication of this paper.

\section{Acknowledgments}

This research was funded by the Liaoning Provincial Social Science Foundation (grant no. L19BJY008) and the Fundamental Research Funds for the Central Universities (grant no. 3132020240).

\section{References}

[1] A. Klettner, T. Clarke, and M. Boersma, "The governance of corporate sustainability: empirical insights into the development, leadership and implementation of responsible business strategy," Journal of Business Ethics, vol. 122, no. 1, pp. 145-165, 2014.

[2] Y. Tang, M. Sun, W. Ma, and S. Bai, "The external pressure, internal drive and voluntary carbon disclosure in China," Emerging Markets Finance and Trade, vol. 56, no. 14, pp. 3367-3382, 2020.

[3] L. Li, Q. Liu, D. Tang, and J. Xiong, "Media reporting, carbon information disclosure, and the cost of equity financing: evidence from China," Environmental Science \& Pollution Research, vol. 24, no. 10, pp. 1-13, 2017.

[4] W. Zhang, M. Zhang, W. Zhang, Q. Zhou, and X. Zhang, "What influences the effectiveness of green logistics policies? A grounded theory analysis," Science of the Total Environment, vol. 714, Article ID 136731, 2020.

[5] Q. Liu and L. Li, "Spatial heterogeneity of government regulation, spatial distance and enterprise carbon information disclosure: an analysis based on the heavy pollution industry in China," International Journal of Environmental Research and Public Health, vol. 16, no. 23, p. 4777, 2019.

[6] P. He, H. Shen, Y. Zhang, and J. Ren, "External pressure, corporate governance, and voluntary carbon disclosure: evidence from China," Sustainability, vol. 11, no. 10, p. 2901, 2019.

[7] J. Peng, J. Sun, and R. Luo, "Corporate voluntary carbon information disclosure: evidence from China's listed companies," The World Economy, vol. 38, no. 1, pp. 91-109, 2015.

[8] L. Liao, L. Luo, and Q. Tang, "Gender diversity, board independence, environmental committee and greenhouse gas disclosure," The British Accounting Review, vol. 47, no. 4, pp. 409-424, 2015.

[9] W. Qian and S. Schaltegger, "Revisiting carbon disclosure and performance: legitimacy and management views," The British Accounting Review, vol. 49, no. 4, pp. 365-379, 2017.

[10] C. Ott, F. Schiemann, and T. Günther, "Disentangling the determinants of the response and the publication decisions: the case of the carbon disclosure project," Journal of Accounting and Public Policy, vol. 36, no. 1, pp. 14-33, 2017.

[11] Z. Liu, S. Abhayawansa, C. Jubb, and L. Perera, "Regulatory impact on voluntary climate change-related reporting by Australian government-owned corporations," Financial Accountability \& Management, vol. 33, no. 3, pp. 264-283, 2017.

[12] F. Faisal, E. D. Andiningtyas, T. Achmad, H. Haryanto, and W. Meiranto, "The content and determinants of greenhouse gas emission disclosure: evidence from Indonesian companies," Corporate Social Responsibility and Environmental Management, vol. 25, no. 6, pp. 1397-1406, 2018. 
[13] D. Li, M. Huang, S. Ren, X. Chen, and L. Ning, "Environmental legitimacy, green innovation, and corporate carbon disclosure: evidence from CDP China 100," Journal of Business Ethics, vol. 150, no. 4, pp. 1089-1104, 2018.

[14] S. Berthelot and A. M. Robert, "Climate change disclosures: an examination of canadian oil and gas firms," Issues in Social and Environmental Accounting, vol. 5, no. 1-2, pp. 106-123, 2011.

[15] W. Qian, J. Hörisch, and S. Schaltegger, "Environmental management accounting and its effects on carbon management and disclosure quality," Journal of Cleaner Production, vol. 174, pp. 1608-1619, 2018.

[16] S. Haque, C. Deegan, and R. Inglis, "Demand for, and impediments to, the disclosure of information about climate change-related corporate governance practices," Accounting \& Business Research, vol. 46, no. 6, pp. 53-60, 2016.

[17] M. C. Jensen and W. H. Meckling, "Theory of the firm: managerial behavior, agency costs and ownership structure," Journal of Financial Economics, vol. 3, no. 4, pp. 305-360, 1976.

[18] E. F. Fama and M. C. Jensen, "Separation of ownership and control," The Journal of Law and Economics, vol. 26, no. 2, pp. 301-325, 1983.

[19] B. Jiang and P. J. Murphy, "Do business school professors make good executive managers?," Academy of Management Perspectives, vol. 21, no. 3, pp. 29-50, 2007.

[20] B. Francis, I. Hasan, and Q. Wu, "Professors in the boardroom and their impact on corporate governance and firm performance," Financial Management, vol. 44, no. 3, pp. 547-581, 2015.

[21] D. M. O'Connell, "From the universities to the marketplace: the business ethics journey," Journal of Business Ethics, vol. 17, no. 15 , pp. 1617-1622, 1998.

[22] A. T. Nuyen, "Ecological education: what resources are there in Confucian ethics?," Environmental Education Research, vol. 14, no. 2, pp. 187-197, 2008.

[23] S. P. Saeidi, M. S. H. Othman, D. Streimikiene, and S. P. Saeidi, "The utilitarian aspect of the philosophy of ecology: the case of corporate social responsibility," Filosofija Sociologija, vol. 29, no. 1, pp. 39-51, 2018.

[24] C. Wang, Q. Zhang, and W. Zhang, "Corporate social responsibility, green supply chain management and firm performance: the moderating role of big-data analytics capability," Research in Transportation Business \& Management, vol. 37, Article ID 100557, 2020.

[25] L. Wang and H. Juslin, "The impact of Chinese culture on corporate social responsibility: the harmony approach," Journal of Business Ethics, vol. 88, no. S3, pp. 433-451, 2009.

[26] X. Du, "Does Confucianism reduce minority shareholder expropriation? Evidence from China," Journal of Business Ethics, vol. 132, no. 4, pp. 661-716, 2015.

[27] X. Du, "Does Confucianism reduce board gender diversity? Firm-level evidence from China," Journal of Business Ethics, vol. 136, no. 2, pp. 399-436, 2016.

[28] S. Bear, N. Rahman, and C. Post, "The impact of board diversity and gender composition on corporate social responsibility and firm reputation," Journal of Business Ethics, vol. 97, no. 2, pp. 207-221, 2010.

[29] Y. Qiu, A. Shaukat, and R. Tharyan, "Environmental and social disclosures: link with corporate financial performance," The British Accounting Review, vol. 48, no. 1, pp. 102-116, 2016.

[30] C. De Villiers, V. Naiker, and C. J. Van Staden, "The effect of board characteristics on firm environmental performance," Journal of Management, vol. 37, no. 6, pp. 1636-1663, 2011.
[31] W. Ben-Amar, M. Chang, and P. Mcilkenny, "Board gender diversity and corporate response to sustainability initiatives: evidence from the carbon disclosure project," Journal of Business Ethics, vol. 142, no. 2, pp. 369-383, 2015.

[32] J. Hollindale, P. Kent, J. Routledge, and L. Chapple, "Women on boards and greenhouse gas emission disclosures," Accounting \& Finance, vol. 59, no. 1, pp. 277-308, 2019.

[33] C. Post, N. Rahman, and C. Mcquillen, "From board composition to corporate environmental performance through sustainability-themed alliances," Journal of Business Ethics, vol. 130, no. 2, pp. 423-435, 2015.

[34] A. Shaukat, Y. Qiu, and G. Trojanowski, "Board attributes, corporate social responsibility strategy, and corporate environmental and social performance," Journal of Business Ethics, vol. 135, no. 3, pp. 569-585, 2016.

[35] M. I. Jizi, A. Salama, R. Dixon, and R. Stratling, "Corporate governance and corporate social responsibility disclosure: evidence from the US banking sector," Journal of Business Ethics, vol. 125, no. 4, pp. 601-615, 2014.

[36] B. W. Husted and J. M. d. Sousa-Filho, "Board structure and environmental, social, and governance disclosure in Latin America," Journal of Business Research, vol. 102, pp. 220-227, 2019.

[37] A. Amran, V. Periasamy, and A. H. Zulkafli, "Determinants of climate change disclosure by developed and emerging countries in Asia Pacific," Sustainable Development, vol. 22, no. 3, pp. 188-204, 2014.

[38] B. Jaggi, A. Allini, R. Macchioni, and C. Zagaria, "The factors motivating voluntary disclosure of carbon information: evidence based on Italian listed companies," Organization \& Environment, vol. 31, no. 2, pp. 178-202, 2017.

[39] J.-M. Prado-Lorenzo and I.-M. Garcia-Sanchez, "The role of the board of directors in disseminating relevant information on greenhouse gases," Journal of Business Ethics, vol. 97, no. 3, pp. 391-424, 2010.

[40] B. W. Lewis, J. L. Walls, and G. W. S. Dowell, "Difference in degrees: CEO characteristics and firm environmental disclosure," Strategic Management Journal, vol. 35, no. 5, pp. 712-722, 2014.

[41] J. Cotter and M. M. Najah, "Institutional investor influence on global climate change disclosure practices," Australian Journal of Management, vol. 37, no. 2, pp. 169-187, 2012.

[42] C. Krishnamurti and E. Velayutham, "The influence of board committee structures on voluntary disclosure of greenhouse gas emissions: Australian evidence," Pacific-Basin Finance Journal, vol. 50, pp. 65-81, 2018.

[43] B. Comyns, "Determinants of GHG reporting: an analysis of global oil and gas companies," Journal of Business Ethics, vol. 136, no. 2, pp. 349-369, 2016.

[44] J. Grauel and D. Gotthardt, "The relevance of national contexts for carbon disclosure decisions of stock-listed companies: a multilevel analysis," Journal of Cleaner Production, vol. 133, pp. 1204-1217, 2016.

[45] M. Freedman and B. Jaggi, "Global warming, commitment to the kyoto protocol, and accounting disclosures by the largest global public firms from polluting industries," The International Journal of Accounting, vol. 40, no. 3, pp. 215-232, 2005.

[46] P. K. Ip, "Is Confucianism good for business ethics in China?," Journal of Business Ethics, vol. 88, no. 3, pp. 463-476, 2009.

[47] G. K. Y. Chan, "The relevance and value of Confucianism in contemporary business ethics," Journal of Business Ethics, vol. 77, no. 3, pp. 347-360, 2008. 
[48] D. Koehn, "Confucian trustworthiness and the practice of business in China," Business Ethics Quarterly, vol. 11, no. 3, pp. 415-429, 2001.

[49] W. Shi and K. Veenstra, "The moderating effect of cultural values on the relationship between corporate social performance and firm performance," Journal of Business Ethics, 2020.

[50] F. Jiang, K. A. Kim, Y. Ma, J. R. Nofsinger, and B. Shi, "Corporate culture and investment-cash flow sensitivity," Journal of Business Ethics, vol. 154, no. 2, pp. 425-439, 2019.

[51] A. W. H. Chan and H. Y. Cheung, "Cultural dimensions, ethical sensitivity, and corporate governance," Journal of Business Ethics, vol. 110, no. 1, pp. 45-59, 2012.

[52] F. N. Ho, H.-M. D. Wang, and S. J. Vitell, "A global analysis of corporate social performance: the effects of cultural and geographic environments," Journal of Business Ethics, vol. 107, no. 4, pp. 423-433, 2012.

[53] S. Chen, Y. Ye, and K. Jebran, "Does confucianism reduce corporate over-investment? Evidence from China," AsiaPacific Journal of Financial Studies, vol. 48, no. 2, pp. 210-235, 2019.

[54] M. Alipour, M. Ghanbari, B. Jamshidinavid, and A. Taherabadi, "Does board independence moderate the relationship between environmental disclosure quality and performance? Evidence from static and dynamic panel data," Corporate Governance: The International Journal of Business in Society, vol. 19, no. 3, pp. 580-610, 2019.

[55] C. H. Cho, J. H. Jung, B. Kwak, J. Lee, and C.-Y. Yoo, "Professors on the board: do they contribute to society outside the classroom?," Journal of Business Ethics, vol. 141, no. 2, pp. 393-409, 2017.

[56] Y. Quan and S. Li, "Are academic independent directors punished more severely when they engage in violations?" China Journal of Accounting Research, vol. 10, no. 1, pp. 71-86, 2017.

[57] Y. Zhuang, "Confucian ecological vision and the Chinese ecocity," Cities, vol. 45, pp. 142-147, 2015.

[58] C. He, "New Confucianism, science and the future of the environment," European Review, vol. 26, no. 2, pp. 368-380, 2018.

[59] P. M. Clarkson, Y. Li, G. D. Richardson, and F. P. Vasvari, "Revisiting the relation between environmental performance and environmental disclosure: an empirical analysis," Accounting Organizations \& Society, vol. 33, no. 4-5, pp. 303327, 2008.

[60] G. Giannarakis, E. Zafeiriou, and N. Sariannidis, "The impact of carbon performance on climate change disclosure," Business Strategy and the Environment, vol. 26, no. 8, pp. 10781094, 2017.

[61] J. Chen, A. Garel, and A. Tourani-Rad, "The value of academics: evidence from academic independent director resignations in China," Journal of Corporate Finance, vol. 58, pp. 393-414, 2019.

[62] D. M. Patten, "Media exposure, public policy pressure, and environmental disclosure: an examination of the impact of tri data availability," Accounting Forum, vol. 26, no. 2, pp. 152171, 2014.

[63] M. Fonseka, T. Rajapakse, and G. Richardson, "The effect of environmental information disclosure and energy product type on the cost of debt: evidence from energy firms in China," Pacific-Basin Finance Journal, vol. 54, pp. 159-182, 2019. 